\title{
O lugar da pesquisa no Mestrado Profissional em Educação
}

\section{The place of research in the Professional Master's Program in Education}

\author{
Marli André \\ Lisandra Princepe ${ }^{2}$
}

\begin{abstract}
RESUMO
O texto discute o lugar da pesquisa no Mestrado Profissional em Educação no Brasil. Na primeira parte, são revistos alguns pontos da sua trajetória, que foi marcada por resistências e desconfianças por parte da comunidade acadêmica. Em seguida, procura-se mostrar aproximações e diferenças entre o Mestrado Profissional e o Acadêmico, acentuando o lugar privilegiado da pesquisa na formação do profissional da educação. Tendo como referência o Mestrado Profissional em Educação: Formação de Formadores da Pontifícia Universidade Católica de São Paulo (PUC SP), indica-se como se tem procurado articular investigação e prática pedagógica na estrutura curricular do curso. Finalmente, apresenta-se uma análise dos trabalhos finais defendidos pelos pós-graduandos desse curso, destacando temas, metodologias e resultados obtidos, o que permite avaliar a consecução dos objetivos pretendidos.

Palavras-chave: pesquisa da prática; Mestrado Profissional; trabalho final de mestrado.
\end{abstract}

\begin{abstract}
This paper discusses the place of research in the Brazilian Professional Master's Program in Education. In the first part we recover part of its history, which is marked by a movement of resistance and distrust by the academic
\end{abstract}

DOI: $10.1590 / 0104-4060.49805$

1 Pontifícia Universidade Católica de São Paulo. Programa de Estudos Pós-graduados em Educação Formação de Formadores - Mestrado Profissional. São Paulo, São Paulo, Brasil. Rua Ministro Godoy, ${ }^{\circ}$ 969, $4^{\circ}$ andar, sala 4B-06. Bairro: Perdizes. CEP: 05015-901. E-mail: marli. andre@gmail.com

2 Universidade Paulista. São Paulo, São Paulo, Brasil. Rua Torres de Oliveira, no 330. Bairro: Jaguaré. CEP: 05047-000. E-mail: lisandramprincipe@gmail.com 
community. Then we try to show the similarities and differences between the Professional and the Academic Masters, emphasizing the relevant place of research in professional training. Taking as reference the professional Master's Degree in Education: Education of Teacher Educators from Pontifícia Universidade Católica de São Paulo (PUC SP), we describe what has been done to connect research and pedagogical practice in the curriculum of the program. Finally, we present an analysis of the final master papers defended by graduate students, which discloses topics, methodologies and results of the studies, allowing us to assess the achievement of the desired objectives.

Keywords: practice research; Professional Master's Degree; final master paper.

\section{Introdução}

No contexto brasileiro, os mestrados profissionais em educação têm uma trajetória bastante curta e sua implantação vem sendo marcada por muita controvérsia, muitos impasses, resistências e desconfianças. O primeiro curso da área foi aprovado em 2009, mas só começou a funcionar em 2010, enquanto em outras áreas do conhecimento essa trajetória começou muito mais cedo.

Mas, por que tantas dúvidas, tantas objeções? Os argumentos usados por aqueles que se opunham à criação dos mestrados profissionais em educação era que eles ameaçavam o futuro da pós-graduação stricto sensu, que se destinava à formação do pesquisador. Em artigo publicado na Revista Educação da PUCCAMP, Severino (2006, p. 11) considerava a proposta dos mestrados profissionais pela Coordenação de Aperfeiçoamento de Pessoal de Nível Superior (CAPES) um grande "equívoco da política nacional de pós-graduação", pois, em suas palavras, poderia trazer "pesadas consequências para o futuro desse nível de ensino". E argumentava que apesar dos cuidados da CAPES no estabelecimento de critérios para recomendação, acompanhamento e avaliação desses cursos, não haveria como "[...] evitar seu impacto negativo na característica básica da pós-graduação stricto sensu, qual seja a pesquisa”. (SEVERINO, 2006, p. 11). $\mathrm{O}$ grande temor era comprometer o que se havia conquistado a duras penas nos últimos anos com a pós-graduação stricto sensu, ou seja, a formação sistemática de pesquisadores, a geração de novos conhecimentos em atendimento às demandas da ciência e da cultura no Brasil. Muitas discussões e embates ocorreram no âmbito da Associação Nacional de Pesquisa e Pós-Graduação em Educação (ANPEd), que levaram os pesquisadores a assumir uma posição de resistência 
frente à possibilidade de criação dos mestrados profissionais na área da educação, com receios similares àqueles expressos por Severino, de perder o espaço da pesquisa e o nível de qualidade conquistado pela pós-graduação brasileira.

Essa visão foi aos poucos mudando e, embora hoje, em 2016, ainda haja alguns redutos de resistência, as críticas diminuíram muito e percebe-se que gradativamente os mestrados profissionais ganham maior confiança e credibilidade. Isso se deve principalmente à forma aguerrida com que os cursos de mestrado profissional vêm se articulando, o que deu origem ao Fórum de Mestrados Profissionais em Educação (FOMPE), que reúne coordenadores dos mestrados profissionais da área, desde 2014, constituindo um espaço de discussões, que tem sido essencial para definir metas comuns e critérios de qualidade para os cursos de mestrado profissional. Os posicionamentos que vêm sendo assumidos pelos participantes do FOMPE, sob a forma de relatórios técnicos, artigos publicados em revistas da área, encaminhamentos à coordenação de área da CAPES têm contribuído para que os preconceitos e as resistências, ainda presentes em alguns grupos da comunidade acadêmica, venham diminuindo ou desaparecendo.

Entre os vários temas abordados nos encontros do FOMPE, destaca-se a identidade dos mestrados profissionais. (HETKOWISKI, 2016; ROMÃO; MAFRA, 2016). O texto de Hetkowiski (2016), que retoma muitos documentos produzidos, indica que a identidade dos Mestrados Profissionais se expressa nas linhas de pesquisa e na proposta curricular dos programas, assim como nos trabalhos finais de conclusão, que devem se voltar para a atividade profissional dos mestrandos.

No centro dessa discussão surgem as dúvidas a respeito das aproximações e diferenças entre o mestrado profissional e o acadêmico. Ribeiro $(2005,2006)$, no posto de Diretor de Avaliação da CAPES, explica que no mestrado acadêmico procura-se, pela imersão na pesquisa, formar o pesquisador a longo prazo. Já no mestrado profisssional também deve haver imersão na pesquisa, mas no sentido de que o mestre profissional possa compreendê-la e saber como utilizá-la. Ribeiro (2006, p. 114) defende, nesses textos, que o mestre profissional seja um "usuário privilegiado da pesquisa". Concordamos, apenas em parte, com a proposição de Ribeiro, no sentido em que defende a imersão dos mestrandos, de ambas modalidades, na pesquisa. No entanto, não corroboramos sua proposição de que os mestres profissionais sejam apenas usuários da pesquisa. O que se propõe é que o profissional seja um pesquisador de sua prática e, para isso, a formação deve estar toda ela orientada para a pesquisa, de modo que o trabalho final de conclusão seja o resultado dessa pesquisa. Nossa posição é que a pesquisa tem um importante papel na formação dos mestres profissionais em educação, pois lhes dá oportunidade de analisar a realidade em que se inserem, localizar áreas críticas que possam ser esclarecidas por um processo sistemático de coleta de 
dados e de referenciais teórico-metodológicos, que lhes permitam atuar mais efetivamente nessa realidade. A pesquisa quando promove a reflexão crítica sobre a prática profissional em educação possibilita o desenvolvimento de indivíduos críticos e criativos.

Os princípios que devem orientar a formação do pesquisador e que foram explicitados em texto anterior (ANDRÉ, 2016) enfatizam a necessidade de envolvimento ativo do sujeito no processo de apropriação de conhecimentos, assim como a criação de coletivos colaborativos, que permitam a partilha de conhecimentos e a construção conjunta de novos conhecimentos. Com apoio nesses princípios, propõe-se uma metodologia (ANDRÉ, 2012, p. 132-134), que objetiva desenvolver, com os profissionais da educação, não só uma atitude de pesquisador, mas também habilidades necessárias à realização de uma pesquisa, tais como: ter como ponto de partida uma problemática, o que vai requerer a aprendizagem da problematização; formular questões orientadoras; aprender a localizar fontes de consulta que ajudem a esclarecer as questões e problemas identificados; conhecer procedimentos metodológicos como relato oral, observação, entrevista, análise documental, registro de áudio e vídeo; construir instrumentos de coleta de dados; analisar dados e escrever um relato da pesquisa.

Se há convicção de que a pesquisa tem um importante lugar na formação do profissional da educação, seja ele professor, coordenador pedagógico, diretor, supervisor, deve-se decidir como concretizar esta proposição.

\section{Uma proposta curricular que visa articular pesquisa e prática profissional}

Nesta seção, apresentar-se-á uma proposta que está centrada na pesquisa e foi desenhada para a formação do profissional da educação que atua na formação de professores da educação básica. O contexto em que se desenvolve essa proposta é o curso de Mestrado Profissional em Educação: Formação de Formadores, da Pontifícia Universidade Católica de São Paulo - PUC SP, que iniciou suas atividades no segundo semestre de 2013. O foco na formação do formador de professores da educação básica decorre do papel fundamental que esse profissional ocupa na efetivação do trabalho pedagógico nas escolas ou em outras instituições educativas. O formador de professores é um profissional que, em geral, assume a função de gestor pedagógico, tornando-se um dos responsáveis pela implementação do Projeto Político-Pedagógico, pela formação contínua dos professores e pelo bom andamento das atividades educativas. Embora 
em alguns países já exista há longo tempo a figura do formador, nos países da América Latina as iniciativas mais sistemáticas de cursos e de constituição de uma carreira do formador começaram a ser implantadas muito recentemente. No Brasil se desconhece a existência de cursos de pós-graduação stricto sensu para formação do formador. Neste sentido, o curso da PUC SP é pioneiro no Brasil.

O curso destina-se a coordenadores pedagógicos, diretores, supervisores e professores das redes pública e privada de ensino. Com duração de dois anos, está organizado em disciplinas e atividades que compõem a estrutura curricular, propiciando aos pós-graduandos oportunidade de reflexão crítica sobre a prática profissional e investigação sobre seu trabalho. Os componentes básicos desta estrutura curricular compreendem: um conjunto articulado de disciplinas obrigatórias e eletivas, um sistema de tutoria acadêmica, seminário de práticas e trabalho final centrado em uma pesquisa.

As disciplinas obrigatórias são balizadas pela área de concentração do curso (formação de formadores - ação pedagógica e avaliação) e pelas linhas de pesquisa (desenvolvimento profissional do formador e práticas educativas; intervenções avaliativas em espaços educativos) incluindo-se entre elas uma disciplina de metodologia de pesquisa. As disciplinas eletivas abordam temas mais específicos, vinculados às linhas de pesquisa. Não só os conteúdos das disciplinas, mas a forma de abordá-las, têm sido um aspecto a que se tem dado muita atenção, pois devem promover a articulação entre teoria e prática.

A tutoria é um componente curricular, consiste em encontros quinzenais de tutores, com pequenos grupos de mestrandos, com duração de uma hora, durante os dois primeiros semestres do curso. Os encontros são agendados na grade horária: uma hora antes ou uma hora depois das aulas das disciplinas obrigatórias. Os tutores são doutorandos dos Programas de Psicologia da Educação e Currículo, da PUC SP, que convidados pelos professores e orientadores se dispuseram a assumir a tarefa de auxiliar os mestrandos a produzir textos, que os levem a demarcar a temática de seu Trabalho Final de Mestrado. As atividades de tutoria são planejadas e acompanhadas pela coordenação do mestrado profissional. As avaliações dessa atividade têm evidenciado contribuição significativa para os mestrandos e para os tutores. (ANDRÉ et al., 2016).

Outra atividade complementar é o seminário de práticas, que foi proposto para possibilitar a socialização dos trabalhos científicos dos mestrandos. A socialização é um componente fundamental no aprendizado da pesquisa, pois essa é validada quando é tornada pública e submetida à apreciação dos pares, que vão poder atestar ou não seu valor. Para que esta meta se concretize, deve haver uma fase de preparo dos trabalhos que serão apresentados e discutidos nos espaços propiciados pelo seminário. Este é realizado em dois dias da semana, no horário das aulas, oferecendo aos mestrandos oportunidade para sistemati- 
zar seus estudos e socializar o conhecimento produzido. Cabe aos mestrandos elaborar um resumo de suas pesquisas para ser apresentado no seminário, sob a forma de pôster ou de comunicação oral. Os tutores colaboram nesta tarefa, oferecendo oficinas de resumo, de pôster e de apresentação de trabalhos. Na organização do seminário envolvem-se os docentes, os tutores e os mestrandos do programa, que participam das várias comissões e da realização do evento.

O trabalho final de conclusão do curso foi alvo de muitas discussões entre os docentes, chegando-se à conclusão que deveria envolver uma pesquisa. As discussões iniciais foram gradativamente aprofundadas com a leitura de textos de autores brasileiros como os de André (2012), Lüdke (2001), Gatti (2014) e de autores estrangeiros, como Elliot (1978, 2009), Tripp (2005), Lerner (2012), que valorizam a pesquisa ancorada nos impasses concretos do trabalho profissional. A proposição de Gatti (2014, não paginado), de que no mestrado profissional a pesquisa visa “[...] evidenciar fatos específicos, pela compreensão de situações localizadas, buscando soluções e propondo alternativas" foi muito bem acolhida e adotada pelos docentes do curso. Chegou-se, assim, a um consenso de que os mestrandos desenvolveriam, como trabalho final de curso, uma pesquisa, que tomasse como referência sua prática profissional.

\section{Os trabalhos finais de conclusão do curso}

Tendo em vista a proposta curricular do Mestrado Profissional Formação de Formadores da PUC SP, centrada na formação do pesquisador da sua prática, buscou-se verificar se os Trabalhos Finais de Conclusão (TFCs) estavam atingindo os objetivos propostos. Indagou-se: referem-se à área de concentração e às linhas de pesquisa do programa? São centrados na prática profissional dos seus autores? Estão relacionados à educação básica?

Procedeu-se inicialmente a uma análise integral dos 44 TFCs defendidos até junho de 2016, para a extração de informações relacionadas à função/cargo ocupado pelo pesquisador, assim como dados pertinentes à pesquisa realizada: objetivos, metodologia e resultados. Em seguida, foram selecionados alguns TFCs, que servirão para ilustrar os resultados que vêm sendo obtidos com a proposta curricular. A intenção não foi realizar uma meta-análise dos trabalhos produzidos no Programa, mas, prioritariamente, verificar em que medida os objetivos do curso vêm sendo alcançados, especialmente quanto a suas relações com as linhas de pesquisa, a articulação entre a pesquisa e a prática profissional dos pós-graduandos e a vinculação dos trabalhos com a educação básica. A 
seleção dos TFCs foi pautada nos seguintes critérios: que contemplassem uma diversidade de contextos de trabalho, cargo/função ocupada pelo pesquisador e que se dirigissem às duas linhas de pesquisa: 1) Desenvolvimento Profissional do Formador e Práticas Educativas; e 2) Intervenções Avaliativas em Espaços Educativos.

Quanto à caracterização dos autores, a maioria ocupa cargo/função de gestor: diretor (6); gerente de avaliação (1), supervisor de ensino (3); coordenador pedagógico/professor coordenador (14), coordenador de núcleo pedagógico (3); formador no Terceiro Setor (5), consultor em formação continuada (1), pedagogo (1). Um grupo menor (9) atua como docente, seja na Educação Infantil, seja nos anos iniciais e finais do ensino fundamental, ou no ensino médio. Um pós-graduado atua como docente no ensino superior, em cursos de Pedagogia.

Quanto aos contextos de trabalho, uma autora atua na Rede Estadual de Educação do Ceará e os demais em São Paulo, dos quais: 18 na rede estadual de educação; 11 em redes municipais (São Paulo, Grande São Paulo e interior); 7 em escolas da rede privada, 5 em instituições do Terceiro Setor; 1 em uma empresa de consultoria em projetos educativos, $1 \mathrm{em}$ um Instituto de Ensino Superior (IES) privado e outro em um Instituto Federal. A maioria dos autores tem vínculo laboral com a rede pública de ensino e atuam como coordenadores pedagógicos, gestores ou professores.

Do total de 44 textos examinados, observou-se que 32 estão vinculados à linha de pesquisa "Desenvolvimento Profissional do Formador e Práticas Educativas", e 12 à linha de "Intervenções Avaliativas em Espaços Educativos". Esta distribuição decorreu da separação dos pós-graduandos, ao final do primeiro semestre do curso, quando fizeram a opção por uma das linhas de pesquisa do curso, o que direcionou a escolha de disciplinas e a temática dos trabalhos finais de conclusão.

A grande maioria dos TFCs (42) teve uma interlocução direta com a educação básica, o que é muito compreensível, uma vez que o curso destina-se à formação de coordenadores pedagógicos, supervisores, diretores e professores para atuar prioritariamente na formação de professores da educação básica. Apenas dois TFCs dirigiram-se indiretamente à educação básica, na medida em que investigaram a formação inicial de professores que ocorre no curso de Pedagogia. Embora o contexto desses dois estudos fosse o ensino superior, as questões investigadas se dirigiam ao preparo do futuro professor para atuar na educação básica.

Na seleção dos candidatos ao mestrado leva-se em conta o critério de vinculação com a educação básica, posteriormente, no desenvolvimento das disciplinas e na orientação do TFC tenta-se reafirmar esse propósito. A análise dos TFCs já defendidos indica que tal propósito vem sendo cumprido. 


\section{As pesquisas sobre o desenvolvimento profissional do formador}

Considerando a linha de pesquisa que tem o foco no desenvolvimento profissional do formador para atuar na formação de professores da educação básica, serão comentados alguns TFCs de autoria de professores, coordenadores pedagógicos e supervisores.

Uma pesquisa relata a formação continuada desenvolvida pela autora (ANTONIUK, 2015), com professores leigos, que atuavam na educação infantil em Moçambique, na África. A pesquisa consistiu na análise crítica do processo de formação, fundamentando-se na pedagogia freireana, o que revelou a importância do diálogo, do respeito à identidade docente e da reflexão crítica sobre a prática. $\mathrm{O}$ estudo possibilitou que a proposta formativa utilizada pela autora fosse não só analisada, mas revista e reestruturada. Em 2016 a pesquisadora foi contratada para implantar o processo formativo em Israel.

Outro trabalho (ZALLA, 2015) analisou uma formação desenvolvida pela autora, professora de artes, centrada em técnicas de narração de histórias e práticas corporais, com professores dos anos iniciais e estagiários de Educação Física, participantes do Programa Mais Educação, de uma rede municipal de educação. Os dados da análise derivaram de diários de bordo elaborados no decorrer do processo; das avaliações escritas pelos participantes e entrevistas com uma coordenadora e uma professora. Os resultados apontaram a contribuição da formação para o bem-estar dos participantes, pois propiciaram a vivência da integralidade (movimento, cognição e afetividade) e a possibilidade de reconhecer seus alunos como pessoas integrais.

As duas professoras analisaram suas experiências como formadoras de professores em projetos de formação continuada e fizeram novas propostas formativas. Os relatos das pesquisas revelaram uma reflexão fundamentada em referenciais teóricos abordados na linha de desenvolvimento profissional, tais como: educação emancipatória, perspectiva sócio-histórica, dimensão identitária, formação permanente, estratégias formativas, trabalho colaborativo.

A seguir serão destacados TFCs que tiveram como sujeitos os coordenadores pedagógicos, os quais revelam as nuances do trabalho desse profissional e apontam para os seguintes aspectos: formação em contexto, dimensão afetiva da formação, análise de necessidades formativas; identificação de estratégias formativas mobilizadoras de práticas pedagógicas efetivas.

Santos (2016), coordenadora pedagógica de uma escola da rede privada, investigou o itinerário de coordenadores pedagógicos (CPs) que atuam nos anos iniciais e finais do ensino fundamental e ensino médio, por meio de uma inter- 
venção colaborativa e participante do qual fizeram parte quatro coordenadores e seis professores. Foram analisados os processos de construção dos planos de formação continuada com foco nos espaços de participação para os professores, nas necessidades surgidas no grupo e nos conhecimentos contemplados como pauta formativa.

Costi (2015), supervisor da rede municipal de ensino, investigou a atuação de uma coordenadora pedagógica que desenvolvia um trabalho reconhecidamente bem-sucedido em uma creche municipal, situada em uma zona de grande vulnerabilidade econômica e social. Um estudo de caso com observação, entrevista e análise documental evidenciou que o trabalho da coordenadora era apoiado no Projeto Político-Pedagógico da instituição e que as decisões eram baseadas na escuta dos professores e em relações afetivas e profissionais, constituindo apoio qualificado e engajado. $\mathrm{O}$ autor relata muitos aprendizados, decorrentes da pesquisa, para sua prática profissional.

Uma coordenadora pedagógica da rede municipal (BONAFÉ, 2015) desenvolveu uma investigação visando identificar estratégias formativas, que no contexto escolar possam mobilizar os professores a aperfeiçoar suas práticas, para lidar com a diversidade de alunos. As entrevistas com quatro coordenadoras pedagógicas evidenciaram que, para elas, havia muitos desafios na execução da formação continuada e pouca clareza sobre como conduzir as ações formativas na escola. A autora elaborou uma proposta para os coordenadores pedagógicos, objetivando aprofundar as discussões sobre formação continuada e estratégias formativas.

Cacero (2016), coordenadora de núcleo pedagógico da rede estadual, desenvolveu uma pesquisa que visou compreender a Aula de Trabalho Pedagógico Coletivo (ATPC) como espaço crítico de colaboração. Os dados foram coletados em duas escolas estaduais, por meio de reuniões gravadas e questionários respondidos por dois coordenadores pedagógicos dos anos finais do ensino fundamental. Com base nos dados, foi elaborada uma proposta para os formadores, de uso da ATPC como espaço crítico de colaboração.

Muito semelhante à pesquisa anterior, um coordenador de núcleo pedagógico da rede estadual (CRUZ, 2016) realizou sua investigação para compreender os significados e sentidos compartilhados na atividade de planejamento de pauta de formação de um grupo de seis coordenadores e um supervisor de uma Diretoria de Ensino. Os dados foram obtidos por meio de gravação de oito reuniões e questionário respondido pelos participantes, os quais evidenciaram que as reuniões constituem espaço fértil de aprendizagem, no qual a negociação de significados está presente.

Um outro estudo (SILVA, 2016) discute um programa de formação continuada, desenvolvido por formadores de uma instituição do terceiro setor, para 
profissionais da educação infantil de um município do estado do Espírito Santo, na perspectiva de duas coordenadoras pedagógicas. Para a coleta de dados foram realizadas entrevistas com as coordenadoras e analisados documentos. Os resultados indicaram a importância das estratégias que favorecem a ação reflexiva como: a tematização e a observação da prática. Também revelaram que as coordenadoras passaram a realizar formações de forma autônoma, não se prendendo a um único modelo.

Ficou evidente, nos estudos citados, que o ponto de origem para a pesquisa foi a prática profissional de seus autores e as inquietações que essa prática suscitou para servir às necessidades identificadas nos contextos investigados ou à identificação das potencialidades de modos de ação já instalados. O olhar para os problemas da prática, que clamam por alternativas de superação, e a elaboração de propostas interventivas parecem indicar a conquista dos objetivos do Mestrado Profissional em Educação: formação de formadores.

\section{As pesquisas voltadas às intervenções avaliativas em espaços educativos}

Os TFCs da linha de pesquisa Intervenções Avaliativas em Espaços Educativos abordaram temas relacionados à avaliação do docente; avaliação de aprendizagem, avaliação de sistema e formação de professores para uso da avaliação de aprendizagem, que coadunam com os objetivos e referenciais teóricos dessa linha de pesquisa.

No âmbito da avaliação docente, um trabalho de uma coordenadora pedagógica (CAMARGO, 2015) relata o processo de construção de uma matriz de referência para avaliação do desempenho de professores que atuam nos anos finais do ensino fundamental, de uma escola privada. O produto final foi a matriz elaborada.

Na temática da avaliação de aprendizagem, destaca-se o estudo de Rades (2015), professora da rede estadual de ensino, que versou sobre a construção de uma proposta de avaliação formativa em Educação Física para o ensino médio, que foi apreciada por sete professores da mesma disciplina e a partir das sugestões foi reformulada. O produto final consistiu em uma rubrica de avaliação para atividades realizadas na quadra e fora dela.

A formação de professores para uso da avaliação de aprendizagem foi objeto de dois trabalhos. Um deles, de autoria de uma Orientadora Educacional e Pedagógica (TONELLO, 2015), consistiu na elaboração de um projeto de 
formação para o uso do portfólio como instrumento de avaliação formativa na educação infantil. O projeto foi discutido com 12 professores em duas sessões de grupo (seis de uma escola municipal de educação infantil e seis de uma escola privada). A partir das contribuições dos docentes, o projeto inicial foi reelaborado de modo a contemplar tópicos que possibilitassem a promoção de mudanças nas práticas avaliativas. A autora vem utilizando o projeto sistematicamente, com grupos de professores de diferentes estados do país. O outro TFC (C. SILVA, 2015), cujo autor é diretor de escola da rede pública estadual, traz a proposição de um jogo (Rolling Playing Game) para a formação continuada, com a intenção de encaminhar uma reflexão crítica sobre as práticas de avaliação da aprendizagem na escola.

A avaliação de sistema da rede estadual de São Paulo foi tema de dois TFCs de autoria de uma supervisora de ensino (GUELLERE, 2015) e de uma diretora de escola. (SOUSA, 2015). O primeiro tomou os dados do Sistema de Avaliação do Rendimento Escolar do Estado de São Paulo (SARESP) e da Avaliação de Aprendizagem em Processo (AAP) a fim de identificar e analisar, por meio de uma discussão coletiva com a equipe gestora (dois professores coordenadores, dois vice-diretores e um diretor) de uma escola, os problemas e dificuldades em relação às avaliações, problematizando os seus usos. Um roteiro para utilização dos dados das avaliações externas foi elaborado com o intuito de apoiar o trabalho do supervisor de ensino e demais gestores escolares. O segundo trabalho traz os resultados de um estudo de caso que teve o objetivo de investigar o uso que professores e coordenadores pedagógicos fazem da AAP. Os dados foram produzidos por meio de observação em uma escola, entrevistas (com o diretor e com o coordenador dos anos finais do ensino fundamental, um supervisor, um técnico da Diretoria de Ensino, dois professores de disciplinas avaliadas e um professor que não participava diretamente da avaliação) e grupo de discussão com 11 alunos. Foram identificadas as diferentes possibilidades de usos da AAP pelos participantes da pesquisa, bem como o potencial da avaliação para o planejamento das ações, visando a melhoria da aprendizagem dos alunos. A diretora de escola, autora do estudo, indicou contribuições da pesquisa para sua prática profissional.

O uso de novas tecnologias na avaliação foi objeto de dois TFCs. Um deles (D. SILVA, 2015) objetivou investigar a forma de apropriação de um ambiente virtual de aprendizagem para a formação continuada dos professores. Seu autor, um professor de matemática da rede pública e formador do Terceiro Setor, ofereceu um curso de formação continuada com o objetivo de familiarizar os coordenadores com os recursos do ambiente virtual, para posterior uso nas atividades de formação. Os três participantes elaboraram uma proposta de formação voltada para sua realidade escolar. O outro TFC (BIANCHI, 2015), 
elaborado por uma professora coordenadora pedagógica da rede estadual, propôs uma formação continuada em $\mathrm{EaD}$, voltada aos supervisores de ensino, com o intuito de instrumentalizá-los a reconhecer as possibilidades do uso pedagógico do celular. A proposta foi estruturada em quatro unidades temáticas a serem desenvolvidas em 20 horas, com atividades participativas e avaliação formativa.

Os TFCs da linha de avaliação abrangeram diferentes perspectivas de avaliação: avaliação docente, avaliação de aprendizagem e de sistema; voltaram-se à atuação profissional de formadores: coordenadores pedagógicos, diretores, supervisores e professores da educação básica. Mantiveram vínculo muito próximo com a realidade das escolas e dos sistemas de ensino e ofereceram propostas de intervenção.

\section{Considerações finais}

Com o objetivo de discutir o lugar da pesquisa no Mestrado Profissional retomou-se, neste texto, alguns aspectos da trajetória dos MPs em educação no contexto brasileiro e discutiu-se algumas aproximações e diferenças entre as modalidades de mestrado stricto sensu "profissional e acadêmico". Tendo como referência o Mestrado Profissional em Educação: Formação de Formadores (FORMEP) da PUC SP, que busca formar coordenadores pedagógicos, diretores, supervisores e demais profissionais para atuar na formação de professores da educação básica, indicou-se como se tem procurado articular investigação e prática pedagógica na estrutura curricular do curso (constituída por um conjunto de disciplinas obrigatórias e eletivas, um sistema de tutoria, seminário de práticas e o trabalho final de conclusão, com ênfase na pesquisa). Por fim, relata-se o resultado da análise dos Trabalhos Finais de Conclusão, já defendidos no FORMEP, extraindo elementos para aferir em que medida os objetivos do curso vêm sendo alcançados.

A análise dos 44 trabalhos defendidos até junho de 2016 evidenciou que 42 tiveram interlocução direta com a educação básica e dois dirigiram-se indiretamente à educação básica, na medida em que investigaram a formação inicial de professores no curso de Pedagogia. Pôde-se observar que de forma geral os objetos de pesquisa estavam centrados na atividade profissional dos autores, fossem eles professores polivalentes ou especialistas, coordenadores pedagógicos de escolas ou de núcleos, supervisores, diretores ou simplesmente formadores. Ficou bastante evidente, na análise, que os TFCs estavam voltados para processos de formação de professores, em vários níveis de ensino: creche, 
educação infantil, anos iniciais e finais do ensino fundamental e ensino médio. Houve maior número de trabalhos dirigidos aos professores do primeiro e segundo segmento do ensino fundamental da rede pública de ensino. A maioria dos TFCs consistiu em uma análise fundamentada de situações concretas da prática profissional e elaboração de propostas para intervenção na realidade analisada.

Os TFCs traduziram a dimensão reflexiva priorizada na estrutura curricular do curso, bem como o rigor do processo de produção dos dados, com o uso de metodologias adequadas às problemáticas investigadas e a discussão de resultados fundamentada nos quadros teóricos pertinentes às temáticas das linhas de pesquisa. Considera-se, assim, que os objetivos do curso vêm sendo atingidos.

\section{REFERÊNCIAS}

ANDRÉ, M. Ensinar a pesquisar: como e para quê? In: VEIGA, I. P. A. (Org.). Lições de Didática. Campinas: Papirus, 2012. p. 123-134.

ANDRÉ, M. A formação do pesquisador da prática pedagógica. Revista Plurais, Salvador, v. 1, n. 1, p. 30-41, jan./abr. 2016.

ANDRÉ, M. E. D. A. de; PEREIRA, R.; PRINCEPE, L. M.; ARANHA, E. G. Tutoria acadêmica no Mestrado Profissional: um aprendizado compartilhado. Revista da FAEEBA-Educação e Contemporaneidade, Salvador, v. 25, n. 47, p. 37-50, set./dez. 2016.

ANTONIUK, M. Revisitando uma prática de formação à luz de referenciais freireanos: uma experiência com professores sem habilitação em Moçambique - África. 75 p. Trabalho Final (Mestrado Profissional em Educação: Formação de Formadores) - Pontifícia Universidade Católica de São Paulo, São Paulo, 2015.

BIANCHI, C. S. T. Uso pedagógico do celular e o papel do Supervisor da rede estadual de ensino de São Paulo. 97 p. Trabalho Final (Mestrado Profissional em Educação: Formação de Formadores) - Pontifícia Universidade Católica de São Paulo, São Paulo, 2015.

BONAFÉ, E. M. O coordenador pedagógico como formador de professores em grupos heterogêneos na escola: as ações de formação e suas implicações. 180 p. Trabalho Final (Mestrado Profissional em Educação: Formação de Formadores) - Pontifícia Universidade Católica de São Paulo, São Paulo, 2015.

CACERO, E. M. Aula de trabalho pedagógico coletivo: atividade crítica de colaboração? 119 p. Trabalho Final (Mestrado Profissional em Educação: Formação de Formadores) - Pontifícia Universidade Católica de São Paulo, São Paulo, 2016.

CAMARGO, S. L. F. Matriz de Avaliação Docente: proposta norteadora para a construção de um processo avaliativo em uma instituição de Educação Básica. 116 p. Trabalho Final 
(Mestrado Profissional em Educação: Formação de Formadores) - Pontifícia Universidade Católica de São Paulo, São Paulo, 2015.

COSTI, R. A atuação de uma coordenadora pedagógica na orquestração de intenções e ações de uma creche de São Paulo. 127 p. Trabalho Final (Mestrado Profissional em Educação: Formação de Formadores) - Pontifícia Universidade Católica de São Paulo, São Paulo, 2015.

CRUZ, F. M. Sentidos e significados sobre o Estudo e o Planejamento para Formação de Formadores: uma experiência com professores coordenadores do Núcleo Pedagógico. 178 p. Trabalho Final (Mestrado Profissional em Educação: Formação de Formadores) - Pontifícia Universidade Católica de São Paulo, São Paulo, 2016.

ELLIOT, J. What is action research in schools? Journal of Curriculum Studies, v. 10, p. $355-357,1978$.

ELLIOT, J. Research-based teaching. In: GEWITZ, S.; MAHONEY, P.; HEXTALL, I.; CRIBB, A. (Ed.). Changing Teacher Professionalism: International trends, challengesand ways forward. London and New York: Routledge, 2009. p. 170-183.

GATTI, B. A. A Pesquisa em Mestrados Profissionais. In: FOMPE - Fórum de Mestrados Profissionais em Educação, I., 2014, Salvador. Trabalhos apresentados... Salvador: UNEB, mar. 2014.

GUELLERE, E. C. M. Trajetória metodológica voltada para superação de problemas pedagógicos, a partir da análise dos dados do SARESP e da Avaliação da Aprendizagem em Processo - AAP. 114 p. Trabalho Final (Mestrado Profissional em Educação: Formação de Formadores) - Pontifícia Universidade Católica de São Paulo, São Paulo, 2015.

HETKOWISKI, T. M. Mestrados Profissionais em Educação: políticas de implantação e desafios às perspectivas metodológicas. Revista Plurais, Salvador, v. 1, n. 1, p. 10-29, jan./abr. 2016.

LERNER, D. Investigação em formação - um trabalho compartilhado. 29 set. 2012. Palestra proferida na Escola de Formação de Professores (EFAP) da SEESP.

LÜDKE, M. O professor e a pesquisa. Campinas: Papirus, 2001.

RADES, T. C. Para além da quadra de aula: uma proposta de avaliação da aprendizagem em Educação Física Escolar no Ensino Médio. 136 p. Trabalho Final (Mestrado Profissional em Educação: Formação de Formadores) - Pontifícia Universidade Católica de São Paulo, São Paulo, 2015.

RIBEIRO, R. J. O Mestrado Profissional na política atual da Capes. $R B P G$, Brasília, v. 2, n. 4, p. 8-15, jul. 2005.

RIBEIRO, R. J. Ainda sobre o Mestrado Profissional. RBPG, Brasília, v. 2, n. 6, p. 313-315, dez. 2006.

ROMÃO, J. E.; MAFRA, J. F. Mestrado profissional: crônica de uma morte anunciada. Revista Plurais, Salvador, v. 1, n. 2, p. 10-23, abr./ago. 2016. 
SANTOS, A. A formação participativa como itinerário metodológico do coordenador pedagógico para implementação de inovações. 109 p. Trabalho Final (Mestrado Profissional em Educação: Formação de Formadores) - Pontifícia Universidade Católica de São Paulo, São Paulo, 2016.

SEVERINO, A. J. O Mestrado Profissional: mais um equívoco na política nacional de pós-graduação. Revista de Educação, Campinas, n. 21, p. 9-16, nov. 2006.

SILVA, C. B. O uso da aventura solo (RPG) na formação de professores com foco na avaliação de aprendizagem. 95 p. Trabalho Final (Mestrado Profissional em Educação: Formação de Formadores) - Pontifícia Universidade Católica de São Paulo, São Paulo, 2015.

SILVA, D. M. O coordenador pedagógico e os ambientes virtuais de aprendizagem - um espaço para a formação de professores. 86 p. Trabalho Final (Mestrado Profissional em Educação: Formação de Formadores) - Pontifícia Universidade Católica de São Paulo, São Paulo, 2015.

SILVA, M. B. T. M. da. Programa de formação desenvolvido em Venda Nova do Imigrante na perspectiva das coordenadoras pedagógicas de Educação Infantil. 102 p. Trabalho Final (Mestrado Profissional em Educação: Formação de Formadores) - Pontifícia Universidade Católica de São Paulo, São Paulo, 2016.

SOUSA, M. E. M. Avaliação da Aprendizagem em Processo: limites e possibilidades de uso em uma Escola da Rede Estadual de São Paulo. 135 p. Trabalho Final (Mestrado Profissional em Educação: Formação de Formadores) - Pontifícia Universidade Católica de São Paulo, São Paulo, 2015.

TRIPP, D. Pesquisa-ação - uma introdução metodológica. Educação e Pesquisa, São Paulo, v. 31, n. 3, p. 443-466, set./dez. 2005.

TONELlO, D. M. M. Portfólios na Educação Infantil: um projeto de intervenção fundamentado na ação formativa. 157 p. Trabalho Final (Mestrado Profissional em Educação: Formação de Formadores) - Pontifícia Universidade Católica de São Paulo, São Paulo, 2015.

ZALLA, T. V. Movimento, cognição, afetividade: o professor em sua integralidade. 91 p. Trabalho Final (Mestrado Profissional em Educação: Formação de Formadores) Pontifícia Universidade Católica de São Paulo, São Paulo, 2015.

Texto recebido em 17 de novembro de 2016. Texto aprovado em 18 de dezembro de 2016. 
